DOI: $10.3901 / J M E .2021 .19 .165$

\title{
绿色制造的理论与技术体系及其新框架*
}

\author{
刘培基 $^{1,2}$ 刘飞 ${ }^{1}$ 王旭 $^{1}$ 尹震爬 $^{3}$ 曹华军 $^{1}$ 李聪波 $^{1}$
}

(1. 重庆大学机械工程学院 重庆 400044;

2. 重庆大学管理科学与房地产学院 重庆 400044;

3. 重庆科技学院机械与动力工程学院 重庆 401331)

\begin{abstract}
摘要: 绿色制造相关研究已有 20 多年, 有必要对绿色制造的内涵、理论与技术体系进行归纳总结, 以支持绿色制造下一阶 段的研究与发展。为此, 在分析和总结绿色制造现有研究的基础之上, 更新和完善了绿色制造的定义, 提出由三个基础理论 (新“三度”理论、资源主线理论以及生命周期理论)和六个主要特性组成的绿色制造理论体系，建立了由 6R 技术原则、三条技 术主线、五类专项技术以及多项产品生命周期管理技术组成的绿色制造技术体系; 最后，通过对绿色制造的根本问题、根本 目标、根本途径、根本路线以及技术主线等进行梳理和总结，建立了绿色制造理论与技术体系的综合框架。
\end{abstract}

关键词: 绿色制造; 理论体系; 技术体系; 基础理论; 体系框架

中图分类号: TG16

\section{The Theory and Technology System of Green Manufacturing and Their New Frameworks}

\section{LIU Peiji ${ }^{1,2}$ LIU Fei $^{1} \quad$ WANG Xu $^{1} \quad$ YIN Zhenbiao $^{3} \quad$ CAO Huajun $^{1} \quad$ LI Congbo $^{1}$}

(1. College of Mechanical Engineering, Chongqing University, Chongqing 400044;

2. School of Management Science and Real Estate, Chongqing University, Chongqing 400044;

3. College of Mechanical and Power Engineering, Chongqing University of Science \& Technology, Chongqing

401331)

\begin{abstract}
The research related to Green Manufacturing (GM) has been over 20 years. To support the next stage of research and development, there is an urgent need to summarize the definition, theories, and technologies of GM. Based on the existing studies, the definition of GM has been updated firstly, followed by the theoretic framework to structure the GM's Three-Degree Theory, Resource Mainline Theory, Product Life Cycle Theory, and Six Main Features. And then, the technological framework to structure GM's 6R principle, three technological mainlines, five categories of specific techniques, and several management techniques across the product life cycle, has been established. Based on the theoretic and technological framework, the fundamental problem, goal, way, and routes have been structured and concluded in a theoretic-technological relation framework.
\end{abstract}

Key words: green manufacturing; theory system; technology system; basic theory; system framework

\section{0 前言}

制造业是国民经济的主体, 是立国之本、兴国 之器、强国之基。但制造业在促进经济增长和丰富 人民物质生活的同时，也带来了严重的资源环境问

* 国家自然科学基金(51775392)和重庆市技术创新与应用示范专项重点 示范(cstc2018jszx-cyzdX0143)资助项目。20201010 收到初稿, 20210411 收到修改稿
题 ${ }^{[1-2]}$ 。英国政府在《未来制造》报告中预测: 到 2050 年全球工业产品需求量将翻一番, 进而材料需求翻 一番、能源需求翻三番 ${ }^{[3]}$ 。如何破解制造业的资源 环境约束，利用有限的资源和生态承载力满足日益 增长的物质需求，是人类社会可持续发展的关键问 题之一。

为此, 一种提升资源效率、降低环境负面影响 的可持续制造模式——绿色制造, 应运而生。绿色 
制造旨在使产品从设计、制造、包装、运输、使用 到回收处理的整个产品生命周期中实现资源利用率 和环境负面影响优化 ${ }^{[4]}$ 。由此可见, 绿色制造是制 造业绿色可持续发展的内在要求和必由之路。

近年来, 欧美等发达经济体均建立了与绿色制 造相关的战略。比如美国在《先进制造伙伴计划 (AMP2.0)》中将 “可持续制造” 列为 11 项振兴制造 业的关键技术之一; 英国将可持续制造(绿色制造) 定义为下一代制造，并制定了 2013-2020 年的可持 续制造发展路线图; 欧洲推行《欧盟地平线 2020 计划(Horizontal 2020)》计划, 投资 30 亿欧元用于 与绿色制造紧密相关的环境、资源效率和稀有材料 等研究; 德国政府提出了《资源效率生产计划》, 并 将 “资源效率 (含环境影响)” 列为工业 4.0 的八大 关键领域之一。

我国也高度重视绿色制造的发展。2006 年 2 月, 国务院发布了《国家中长期科学和技术发展规划纲 要(2006-2020 年)》, 将绿色制造列为制造业科技发 展的三大方向之一。2011 年 7 月, 科技部发布了《国 家 “十二五” 科学和技术发展规划》, 明确提出 “重 点发展先进绿色制造技术与产品, 突破制造业绿色 产品设计、环保材料、节能环保工艺、绿色回收处 理等关键技术”。2015 年 5 月, 国务院发布了《中 国制造 2025》, 提出 “全面推行绿色制造” , 实施 “绿色制造工程”, 明确了 “构建绿色制造体系, 走生态文明发展道路”。总体来看, 九五至十三五 期间, 对绿色制造的基础理论与共性技术进行了研 究, 并逐步向产业化应用发展。

如今, 在我国即将开启全面建设社会主义现代 化国家新征程之际, 绿色制造也面临不少的新要求、 新矛盾以及新挑战。为支持绿色制造下一阶段的研 究与发展, 有必要对绿色制造的内涵、理论与技术 体系进行归纳总结。尽管作者们早年间曾初步建立 了绿色制造理论体系和技术体系框架 ${ }^{[5-7]}$, 但随着绿 色制造研究的不断发展和深入, 我们发现其中部分 内容还有待进一步完善和提升, 特别是还缺乏对绿 色制造的根本问题、根本目标、根本途径、根本路 线以及技术主线等进行梳理和总结。为此, 本文试 图对上述问题进行再思考和探讨。

\section{1 绿色制造定义的再思考}

自 1996 年美国制造工程师协会在底特律年会 上发布了《绿色制造》蓝皮书 ${ }^{[8]}$ 至今, 已有 20 多年。 期间, 国内外学者对绿色制造的定义进行了大量研
究; 由于绿色制造尚处于不断发展中, 并未取得较

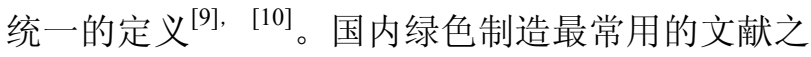
一是于 1997 在全国先进生产模式与制造哲理研讨 会上提出的绿色制造定义 ${ }^{[4]}$ 。

绿色制造，是一个综合考虑环境影响和资源消 耗的现代制造模式，其目标是使产品从设计、制造、 包装、运输、使用到回收处理的整个产品生命周期 中, 对环境负面影响最小, 资源利用率最高, 并使 企业经济效益和社会效益协调优化。

上述定义中，由于环境负面影响的减小是一个 逐步减小的相对过程, 也是一个最终极限为零的极 限过程; 因此, 将用 “对环境负面影响极小” 替代 “对环境负面影响最小”。同理, 由于资源利用率 是一个逐步提升的相对过程, 也是一个最终极限为 资源利用率 $100 \%$ (即完全循环利用)的极限过程; 因 此, 将用 “资源利用率极高” 替代 “资源利用率 最高”。

在上述定义的提出背景下, 环境效益常常被视 为社会效益的一部分。但随着环境问题受到的关注 度越来越高, 表征降低环境负面影响和提升环境质 量的环境效益被单独提及的频率也越来越高, 故而 绿色制造的内涵也逐渐由 “经济效益和社会效益协 调优化” 转变为 “经济、环境和社会效益协调 优化”。

近年来, 对绿色制造环境效益的认识逐步扩展 到了 “生态效益”。生态效益常见的定义是指人们在 生产中依据生态平衡规律, 使自然界的生物系统对 人类的生产、生活条件和环境条件产生的有益影响 和有利效果 ${ }^{[9]}$ 。生产、生活条件是以资源为基础的, 因此生态效益包括了环境效益和资源效益。由于绿 色制造是一个综合考虑环境影响和资源消耗的现代 制造模式，因此，在绿色制造的定义中，将采用生 态效益替代环境效益。

综上所述，将绿色制造定义调整为如下：绿 色制造, 是一个综合考虑环境影响和资源消耗的 现代化制造模式; 其目标是使产品从设计、制造、 包装、运输、使用到回收处理的整个产品生命周 期中, 对环境负面影响极小, 资源利用率极高, 并使企业经济效益、社会效益和生态效益协调 优化。

尽管不同发展阶段对于经济效益、社会效益 和生态效益的侧重点或需求度不同, 但绿色制造 的宏观目标始终是寻求经济效益、社会效益和生 态效益的协调优化以支持经济社会的可持续 发展。 


\section{2 绿色制造理论体系及其新框架}

目前, 绿色制造的理论体系尚在研究和发展中。 在此, 根据作者们多年来的研究 ${ }^{[5-7]}$, 并参考国内外 有关的研究成果 ${ }^{[12-14]}$, 建立了绿色制造的初步理论 体系及其框架。其主要内容包括以下三个方面的基 础理论和六个方面的主要特性。

\section{1 绿色制造的三个基础理论}

\subsection{1 绿色制造的新 “三度” 理论}

作者们曾提出了由 “生产度”、“绿色度” 和 “协 调度” 组成的绿色制造 “三度” 理论 ${ }^{[5]}$ 。其中, “生 产度” 描述生产量的大小, “绿色度” 反映绿色的程 度或对环境的友好程度, 而 “协调度” 表示 “绿色 度”与 “生产度” 的协调关系。

但随着绿色制造研究的不断深入, 发现: 绿色 制造需要实现的是产品生命周期全过程的经济效 益、社会效益和生态效益的协调, 而仅仅用 “绿色 度” 和 “生产度” 是难以描述的。

为此，参考可持续发展战略中的 “三度” 理 论 ${ }^{[15]}$ 和上述绿色制造 “三度” 理论, 提出由 “制造 度” (图 1)、“绿色度” (图 2)和 “协调度” 组成的绿 色制造新 “三度” 理论(图 3)。

(1) 制造度。制造有 “小制造” 和 “大制造” 之分。“小制造”一般理解为产品生命周期中的生产 制造环节, 而 “大制造” 涉及产品全生命周期的各 个环节。

如图 1 所示, 从大制造的角度来看, 制造度就 是对产品生命周期全过程的时间、质量、成本和服 务四个目标维度的优劣程度的综合描述, 包括产品 生命周期过程的设计度、生产度、包装度、运输度、 使用度、回收度和处理度。

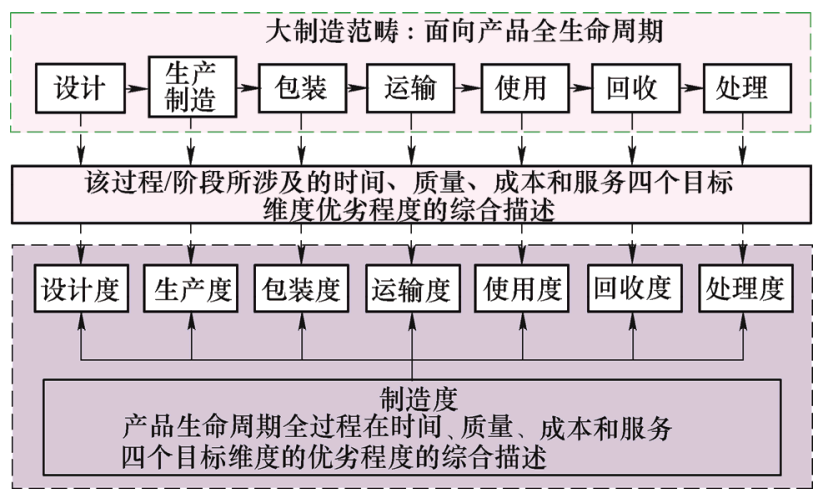

图 1 绿色制造的制造度

从小制造的角度来看, 制造度就是对生产制造 过程的生产率、生产质量、生产成本以及生产服务
优劣程度的综合描述。显然, 生产率越高、输出产 品越多、生产质量以及生产服务越好以及生产成本 越低, 企业取得较大经济效益的机会越大、社会生 产力越高。因此, “制造度” 也是对企业经济效益以 及社会效益的一种综合描述。

（2）绿色度。绿色制造的根本问题在于制造业 带来的资源消耗和环境负面影响问题。因此, 采用 “绿色度”用于综合描述产品生命周期全过程的资源 和环境两个目标维度的优劣程度。

如图 2 所示, 从大制造的范畴来看, 绿色制造 的 “绿色度” 包括产品生命周期过程的设计绿色度、 生产绿色度、包装绿色度、运输绿色度、使用绿色 度、使用绿色度、回收绿色度以及处理绿色度。其 中, 产品生命周期全过程绿色度越大, 即资源利用 率越高、环境负面影响越小，利用有限的资源满足 社会上人们日益增长的物质文化需求的可能性也就 越高。因此, “绿色度” 的概念也是对产品生命周期 全过程的生态效益和社会效益的一种综合描述。

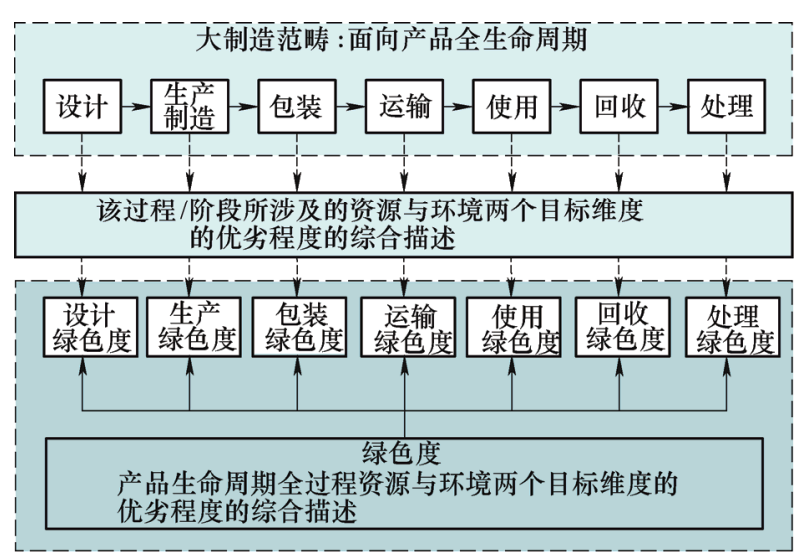

图 2 绿色制造的 “绿色度”

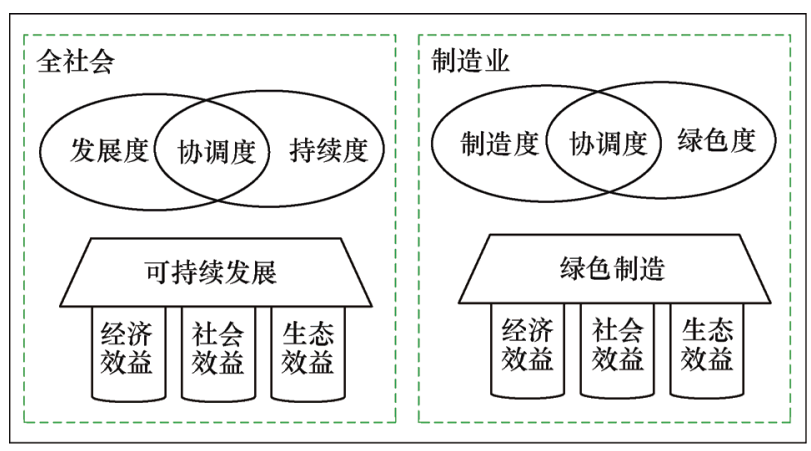

图 3 可持续发展与绿色制造的 “三度”

（3）协调度。一方面, 绿色制造的 “协调度”, 其内涵在于强调制造度与绿色度的协调关系, 代表 了经济效益、社会效益和生态利益的协调。另一方 面, 强调设计过程的设计度与设计绿色度协调、生 产制造过程的生产度与生产绿色度协调、包装过程 
的包装度与包装绿色度协调、运输过程的运输度与 运输绿色度协调、使用过程的使用度与使用绿色度 协调、回收过程的回收度与回收绿色度协调以及处 理过程的处理度与处理绿色度协调。

综上所述, 绿色制造的 “三度” 理论表明: 绿 色制造的根本问题在于制造业带来的资源消耗和环 境负面影响问题; 绿色制造的根本目标在于协调和 优化 “制造度” 和 “绿色度”, 实现经济效益、社会 效益和生态效益的协调优化。

2.1.2 绿色制造的资源主线理论

绿色制造定义中所述的资源, 可分为狭义资源 和广义资源两种: 狭义资源, 也叫物能资源, 由物 料、能源、水、设备、其他支持设施(如厂房、土地) 等资源组成; 而广义资源还包括资金、技术、信息、 人力等资源。本文所涉及的资源主要是指物能资源, 重点是物料和能源。

作者曾提出了绿色制造的资源主线论, 即绿色 制造的根本途径是优化制造资源的流动过程, 使得 资源利用率尽可能高, 废弃资源尽可能少 ${ }^{[5]}$ 。经过 进一步地深化和完善, 形成了以下三个方面的资源 主线理论内涵。

（1）资源消耗问题，不仅涉及有限资源如何可 持续利用问题, 而且也是产生环境问题的主要根 源 ${ }^{[5]}$ 。制造业在将制造资源转变为产品的制造过程 中以及在产品的使用和报废处理过程中, 消耗了大 量资源, 同时产生了大量的废弃物和排放(如废液、 废气和固体废弃物等), 这是产生制造业资源环境问 题的主要根源。

（2）使用绿色资源、优化资源消耗过程是解决 制造业资源环境问题的重要途径之一。其中, 绿色 资源主要包括无污染易降解材料、清洁能源等。

（3）促进资源再利用与循环流动是解决制造业 资源环境问题的另一条重要途径。制造业将大量的 资源转换成产品, 如果产品报废后不能降解或不能 再利用, 则会造成资源短缺、环境污染等系列问题。 回收废旧产品或零部件, 促进资源再利用与循环流 动是解决这些问题的关键。

综上所述, 资源主线理论表明: 绿色制造的根 本途径在于提升资源利用率，包括使用绿色资源、 优化资源消耗过程以及促进资源循环与再利用。

\subsection{3 绿色制造的产品生命周期理论}

产品生命周期是指产品从设计、制造、包装、 运输、使用到报废处理等所经历的全部过程, 相当 于一个生命体从孕育(设计)、诞生(制造)、生存(运
维)……到生命终结及处理(报废处理)的生命周期全 过程。绿色制造的产品生命周期理论包含以下三个 方面的内涵:

（1）绿色制造产品生命周期的设计、生产制造、 包装、运输、使用到报废处理等全部过程是相互关 联、相互作用的一个有机整体。

（2）产品生命周期涉及产品设计过程、生产制 造过程、运输过程、使用过程以及回收再制造过程 所关联的制造系统或运行支持系统。每个过程和系 统都需要消耗资源, 都需要提升资源利用率、降低 环境负面影响。

(3) 有的产品或其有关零部件存在多生命周期 过程。多生命周期不仅包括本代产品生命周期的全 部过程, 而且还包括产品老化或报废后, 产品或其 有关零部件再制造后循环使用和循环利用等过程。 产品多生命周期工程理论是指从产品多生命周期的 时间范围来综合考虑环境影响与资源综合利用问题 和产品寿命问题的有关理论和工程技术的总称，其 目标是在产品多生命周期时间范围内, 延长产品回 用时间, 提高资源综合利用率, 并降低对环境的负 面影响。

综上所述, 绿色制造的产品生命周期理论表明: 绿色制造的根本路线在于从产品全生命周期视角出 发, 面向资源效率提升, 系统优化产品生命周期全 过程(包括部分产品的多生命周期)及其所关联制造 系统或运行支持系统。

\section{2 绿色制造的主要特性}

在绿色制造的新“三度”理论、资源主线理论和 产品生命周期理论基础之上, 绿色制造还具有物料 流闭环特性、能量效率特性、大制造系统特性、大 数据特性、多目标决策属性、集成特性等多方面的 特性。

2.2.1 绿色制造的物料流闭环特性、多目标决策属 性、集成特性

物料流闭环特性、多目标决策属性、集成特性 已在文献[6]和文献[16-18]中作了详细描述。其中， 物料流闭环特性是指绿色制造的物料流由开环物料 流(即传统制造的物料流，如图 4 实线箭头部分所示) 和逆向物料流组成(如图 4 虚线箭头部分所示)组 成 ${ }^{[5]}$; 多目标决策属性是指绿色制造的决策目标包 括快速响应能力 $\mathrm{T}$ 、产品质量 $\mathrm{Q}$ 、成本 $\mathrm{C}$ 、服务 $\mathrm{S}$ 、 资源利用率 $\mathrm{R}$ 和环境负面影响 $\mathrm{E}$ 等六个方面; 集成 特性是指绿色制造的领域集成、问题集成、效益集 成、信息集成、过程集成、目标集成以及社会集成。 


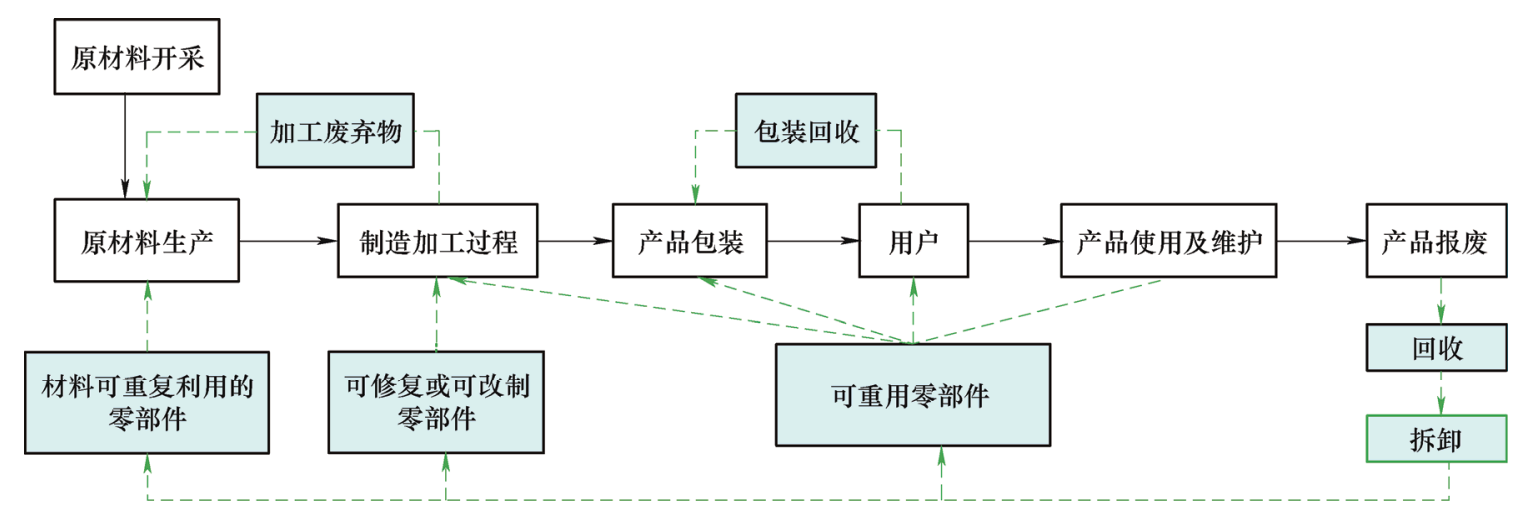

图 4 绿色制造的物料流闭环特性

\subsection{2 绿色制造的能量效率特性}

能量是制造业中除了物料资源之外的另一种重 要资源, 贯穿于产品全生命周期的全过程。因此, 绿色制造具有全生命周期的能量消耗与能量效率特 性, 可从以下三个方面来反映。

（1）制造装备能量效率特性。制造装备是企业 的能量消耗主体, 在完成各式各样产品的加工过程 中, 都伴随着复杂的能量消耗和能量效率特性。来 自制造系统外部的能量(如电能), 流向制造系统的 各有关环节或子系统, 一部分用以维持各环节或子 系统的运转, 另一部分通过传递、损耗、储存、释 放、转化等有关过程, 以完成制造过程的有关功能。

(2) 产品制造过程的能量效率特性。从产品生 命周期的角度来看, 产品制造过程的能量消耗一般 较大; 对于使用阶段不消耗能量的产品而言, 其制 造过程能耗占比更大。产品制造过程的能量消耗受 产品的设计方案、工艺种类和工艺路线的选择等因 素影响, 具有非常复杂的能量效率特性 ${ }^{[19]}$ 。

(3) 产品运行过程的能量效率特性。产品运行 过程的能量效率特性, 决定了产品使用阶段的耗能 水平。优化该能效特性, 可为用户带来显著的效益。 比如开发燃油效率高的飞机或汽车, 可降低客户的 使用成本, 减少环境排放, 也更受市场欢迎。

\subsection{3 绿色制造的大制造系统特性}

绿色制造的大制造系统特性是指需要从产品生 命周期全过程所涉及的大制造系统角度来综合考虑 和解决制造业的资源环境问题。

制造系统是制造过程及其所涉及的硬件、软件 和人员所组成的一个将制造资源转变为产品或半产 品的输入输出系统。产品生命周期各阶段所对应的 制造系统或运行支持系统, 均是消耗资源的输入输 出系统, 都符合制造系统的定义, 因此它们组成了 一个涉及面更大的产品生命周期大制造系统。

另一方面, 现代产品的生产模式往往是多个跨
领域、跨区域的企业所参与的供应链协作模式。只有 从更大的制造系统范围内考虑和解决制造业的资源 消耗和环境负面影响问题，才能真正实现绿色制造。

因此，绿色制造具有显著的大制造系统特性。

\section{2 .4 绿色制造的大数据特性}

绿色制造的大数据特性是指绿色制造需要对产 品生命周期大数据以及绿色制造支撑大数据进行管 理和分析以支持产品生命周期的绿色优化决策。

一方面, 如图 5 所示, 产品生命周期时间跨度 大、资源消耗环节多，其中包含非常复杂的信息流， 数据量庞大; 如何收集、管理和分析产品生命周期 的大数据, 是产品生命周期评价和优化的基础。

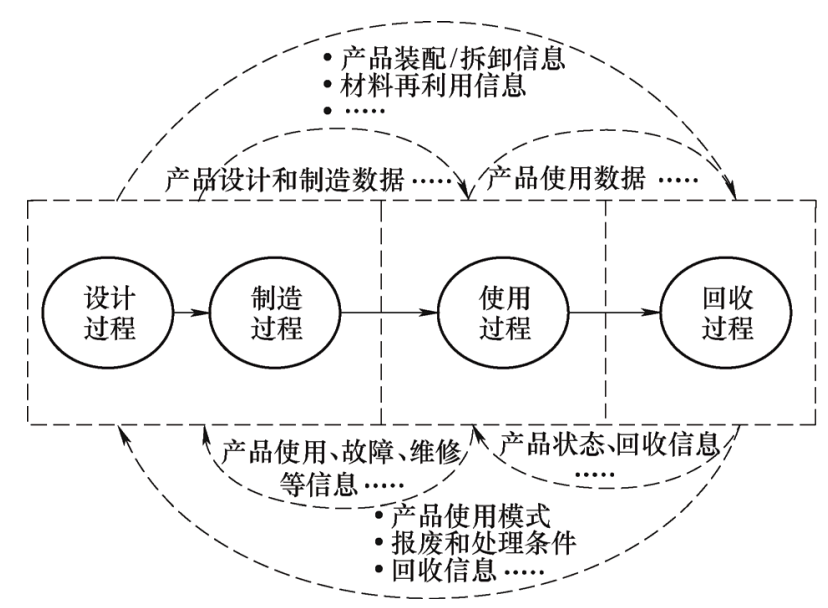

图 5 绿色制造大数据: 产品生命周期数据示意图

另一方面, 绿色制造的实施, 特别是绿色设计 和绿色工艺规划, 离不开绿色设计数据、绿色材料 数据、绿色工艺数据、绿色运维数据等绿色制造大 数据的支持。

\section{3 绿色制造的理论体系框架}

综上所述, 可建立如图 6 所示的一种绿色制造 理论体系新框架。

一方面，在新框架中，绿色制造的 “三度” 理 论、资源主线理论以及产品生命周期理论三个基础 
理论相互关联，指出了绿色制造的根本问题、根本 目标、根本途径以及根本路线。

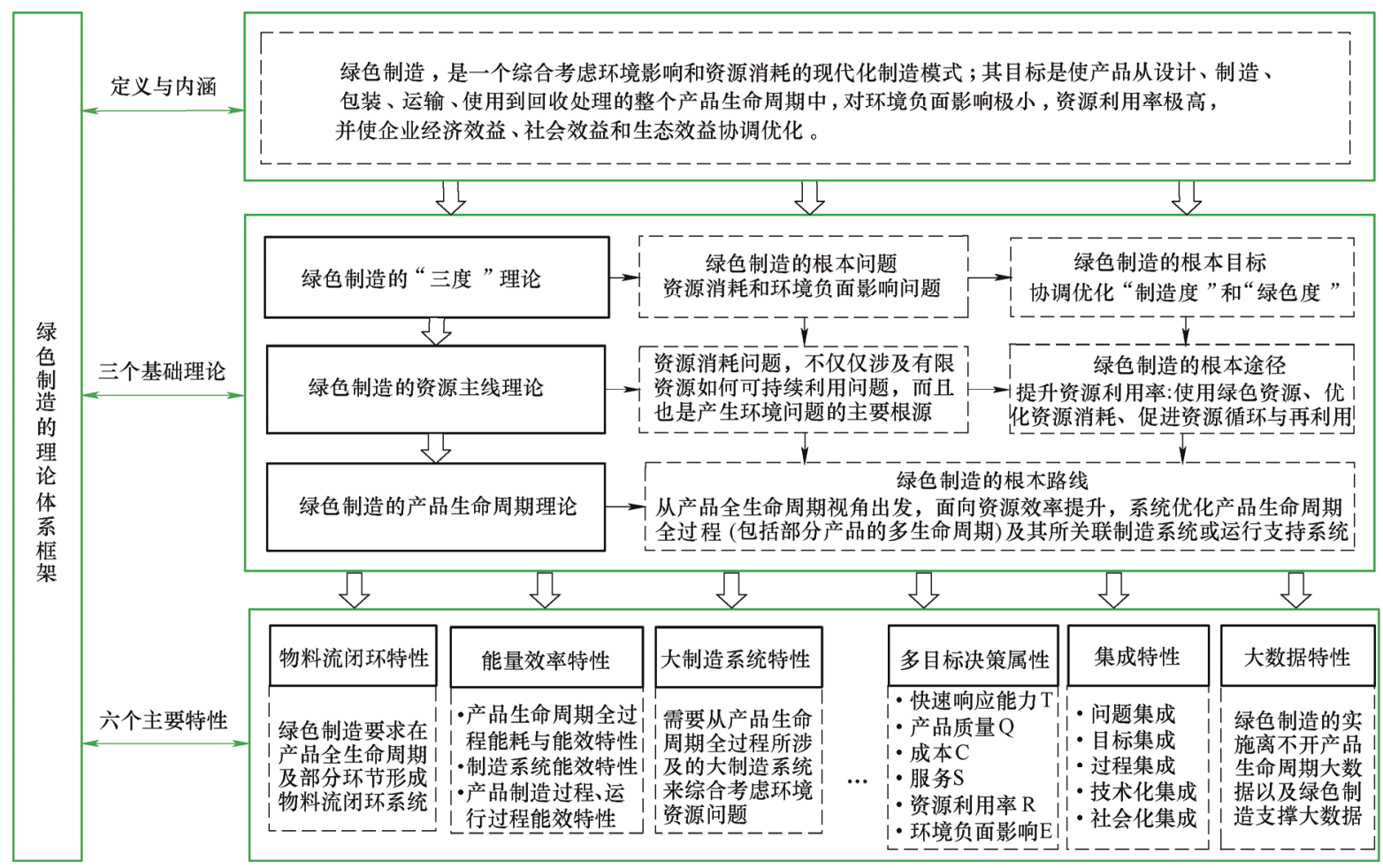

图 6 绿色制造的理论体系框架

另一方面, 在新框架中, 三个基础理论贯穿绿 色制造的物料流闭环特性、能量效率特性、大制造 系统特性、多目标决策属性、集成特性、大数据特 性等六个方面的主要特性, 并最终形成一个相互关 联、相互作用的有机整体。

其中, 由于绿色制造尚处于研究和发展中, 还 可能存在其他绿色制造特性尚未发掘, 因此在图中 以省略号进行表达。

\section{3 绿色制造技术体系及其新框架}

\section{1 绿色制造技术的 $6 \mathrm{R}$ 原则}

绿色制造技术是解决制造业资源消耗和环境负 面影响的关键。绿色制造的资源主线理论和产品生 命周期理论建立了绿色制造的根本途径和根本路 线, 即优化产品生命周期全过程(包括部分产品的多 生命周期过程)的资源消耗, 提升资源效率), 这要 求绿色制造技术应具有以下 6 个方面的原则(简称 6R 原则, 图 7) ${ }^{[6,12,14]}$ 。

(1) 减量化(Reduce)要求在产品生命周期中减 少资源消耗产生，特别强调在产品设计阶段面向产 品生命周期设计绿色产品, 从源头上减少产品生命
周期全过程的资源消耗。

(2) 再利用(Reuse)要求产品回收后, 或作为直 接再利用, 或经修复、翻新、再制造后再使用, 或 将产品(或其零部件)作为其他产品(或零部件)予以 使用;

(3) 再生循环 (Recycle) 旨在将废物直接作为原 料进行利用或者对废物进行再生利用。

(4) 再恢复(Recover)旨在通过修复或再制造, 使得产品及其零部件的功能得到恢复。

(5) 再设计(Redesign)旨在以优化重用原有退役 设备及零部件资源为目标, 对退役设备及零部件的 功能、结构、外观等进行再设计。有时候, 再设计 也指产品的二次优化设计。

(6) 再制造(Remanufacturing) 将废旧产品及零 部件作为制造资源，进行评价和再加工制造，使得 废旧产品的功能和质量得到恢复，甚至超过新品， 从而提升资源循环利用率、降低环境负面影响。

\section{2 绿色制造的三条技术主线}

在绿色制造基础理论、主要特性以及 $6 \mathrm{R}$ 原则 的指导下，结合围绕产品生命周期的各个具体阶段 及其所关联的系统，绿色制造呈现以下三条技术主 线(图 8)。 


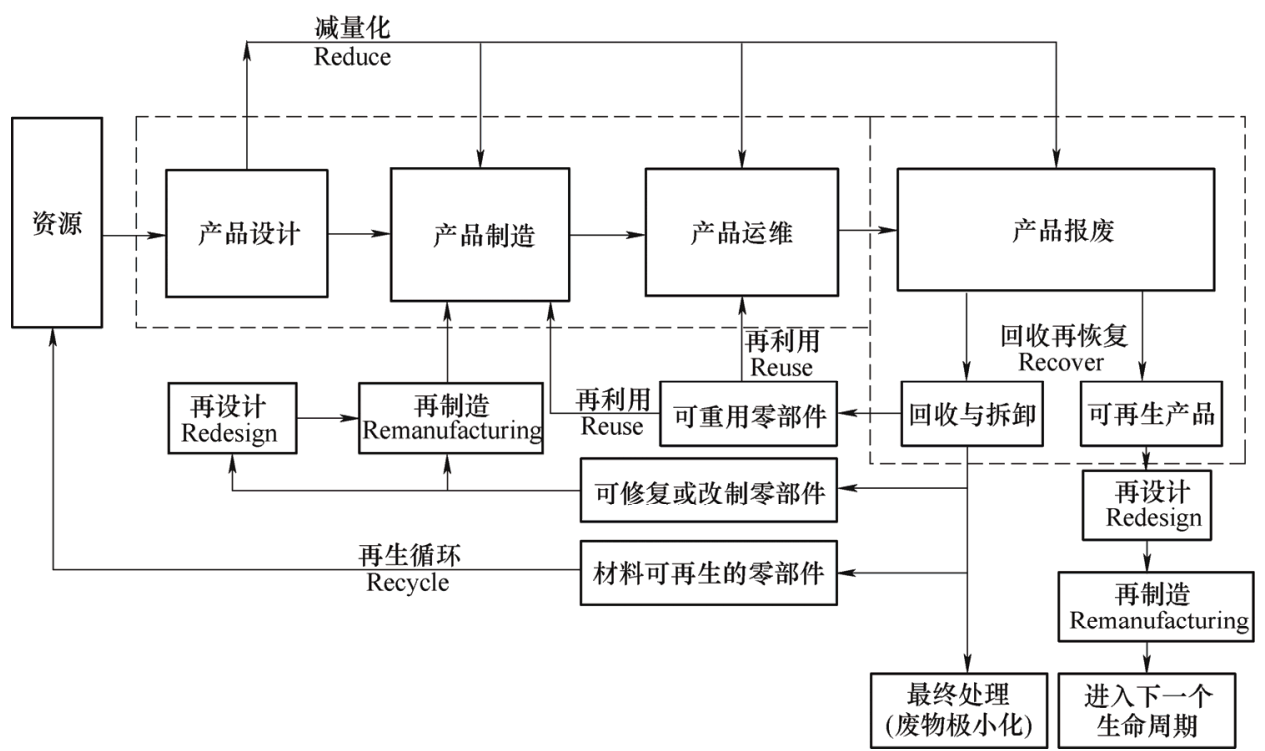

图 7 绿色制造的 $6 \mathrm{R}$ 原则

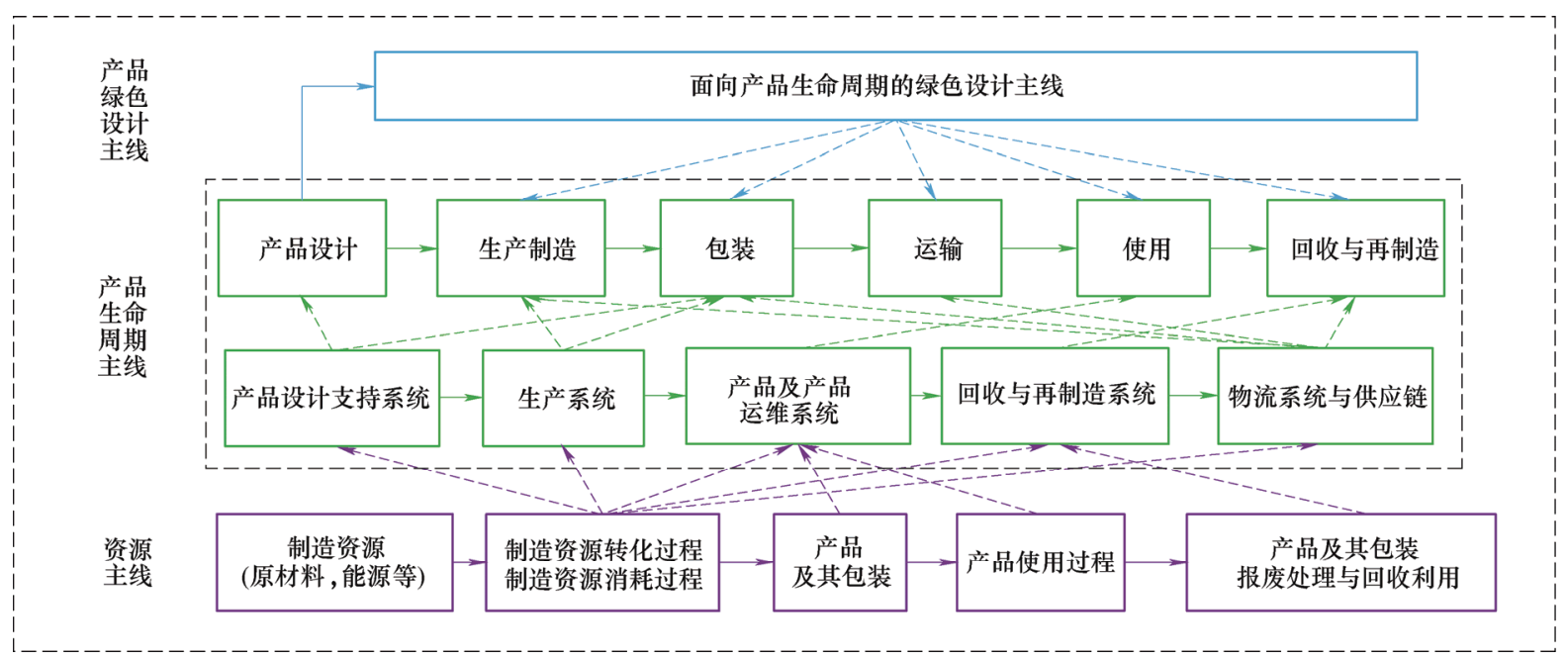

图 8 绿色制造的三条技术主线

首先，资源主线理论要求优化制造资源消耗过 程并促进资源循环流动, 使得资源效率极高、废弃 资源极少(目标为零)。基于此, 形成了绿色制造技 术的资源主线，即构建面向制造资源的转化与消耗 过程、已加工制造资源(即产品及其包装)的流动过 程、产品的资源消耗过程以及产品及其包装的资源 回收处理过程的绿色制造技术。

其次, 绿色制造的产品生命周期理论要求从产 品全生命周期的系统角度出发, 优化产品生命周期 全过程(包括部分产品的多生命周期过程)的资源消 耗与效率以及降低环境负面影响。基于此, 形成了 绿色制造技术的产品生命周期主线, 即包括以产品 生命周期中的各个阶段为优化对象的产品绿色设计 技术、产品工艺绿色规划技术、产品绿色包装技术、 产品绿色运维技术、产品绿色供应链管理技术以及 产品绿色回收与再制造技术。

再次, 绿色制造的产品生命周期理论还形成了
旨在产品设计阶段实现资源消耗与效率以及环境负 面影响源头控制的产品绿色设计主线, 即面向产品 生命周期的产品设计主线。产品绿色设计主线, 着 重考虑面向生产、运行与维护、供应链、回收与再 制造等设计技术以及与传统设计技术的集成, 突出 了绿色设计的重要性。

绿色制造技术的资源主线、产品生命周期主线 以及产品绿色设计主线, 各有侧重、相辅相成, 共 同引导着绿色制造技术的研究和发展。

\section{3 绿色制造的专项技术体系及技术体系框架}

基于绿色制造技术的 $6 \mathrm{R}$ 原则和三条技术主线， 可提出一个由绿色设计、绿色生产、绿色运维、绿色 回收与再制造以及绿色供应链管理五类专项技术和多 项产品生命周期管理技术组成的绿色制造技术体系。

其中，绿色包装技术是绿色制造技术中的重要 组成部分。由于包装也可视为一种特殊产品, 同时 产品涉及的绿色制造技术也包含了绿色包装技术。 
因此, 在建立绿色制造技术体系 时, 绿色包装技术 没有单独列出, 而是分散在各项技术体系中。

下面, 将依次对上述五类专项技术以及产品生 命周期管理技术进行总述。

（1）绿色设计技术。产品设计环节, 在很大程 度上决定了产品制造过程、运输过程、使用过程的 资源消耗以及回收过程的资源消耗与处理。绿色制 造要求在产品设计阶段便面向产品生命周期全过
程, 将减少环境负面影响和降低资源消耗的措施纳 入设计之中, 使得产品全生命周期过程对环境的负 面影响极小, 资源利用率极高。通过梳理和总结现 有文献[20-23], 图 9 给出一种由 9 项功能技术和 3 项支撑技术组成的绿色设计技术体系; 这些绿色设 计技术将融入产品结构优化、功能优化、材料优化 以及包装优化等过程, 以支持开发绿色产品。

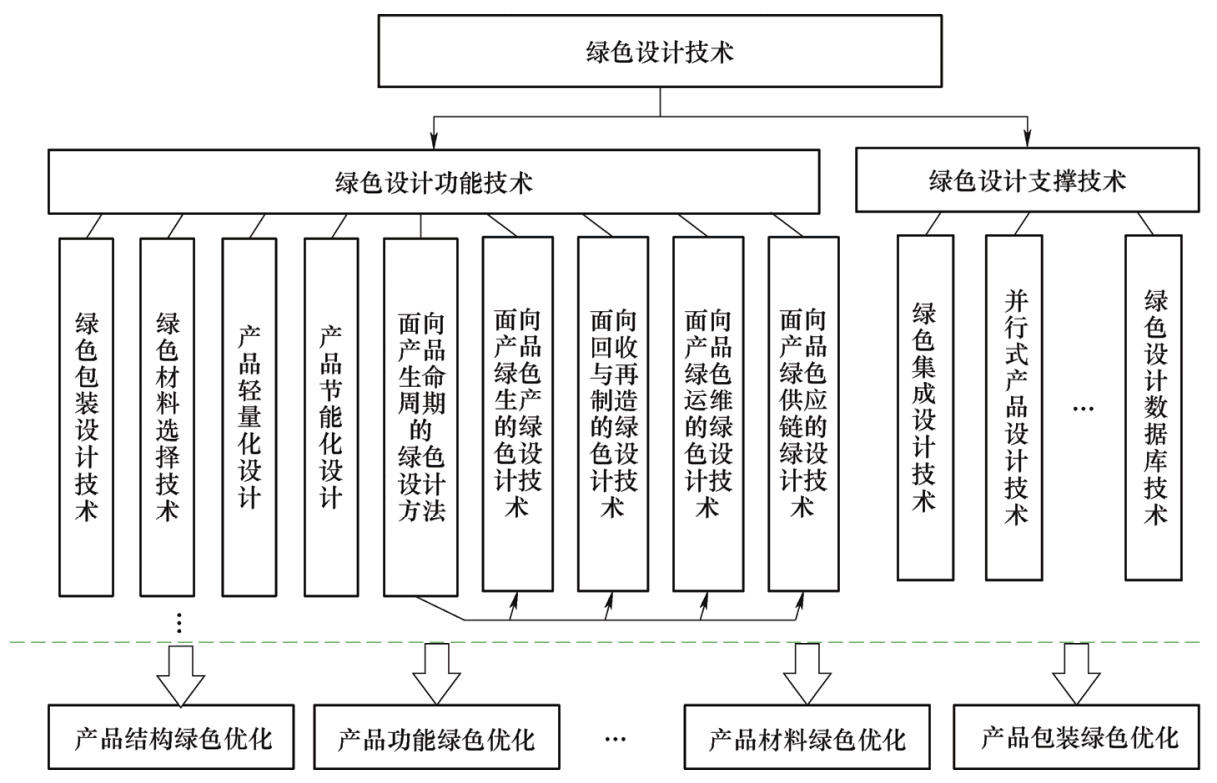

图 9 绿色设计技术体系

（2）绿色生产技术。绿色生产, 又常称为清洁 生产, 要求通过不断采取改进设计、使用清洁的能 源和原料、采用先进的工艺技术与设备、改善管理、 综合利用等措施, 提高资源利用效率, 减少或者避 免生产过程中污染物的产生和排放, 以减轻或者消 除对人类健康和环境的危害。通过梳理和总结现有 研究 $^{[6], ~[24]-[28]}$, 可从产品、工艺、生产系统三个角
度, 形成一种由绿色工艺及其装备开发技术、产品 工艺绿色规划技术以及生产系统绿色优化技术三类 技术组成的绿色生产技术体系, 如图 10 所示。其中, 图 10 只是提供了一种分类方法, 而各绿色生产技术 即为实现制造过程资源的减量化(Reduce)、再利用 (Reuse)和再生循环(Recycle)。

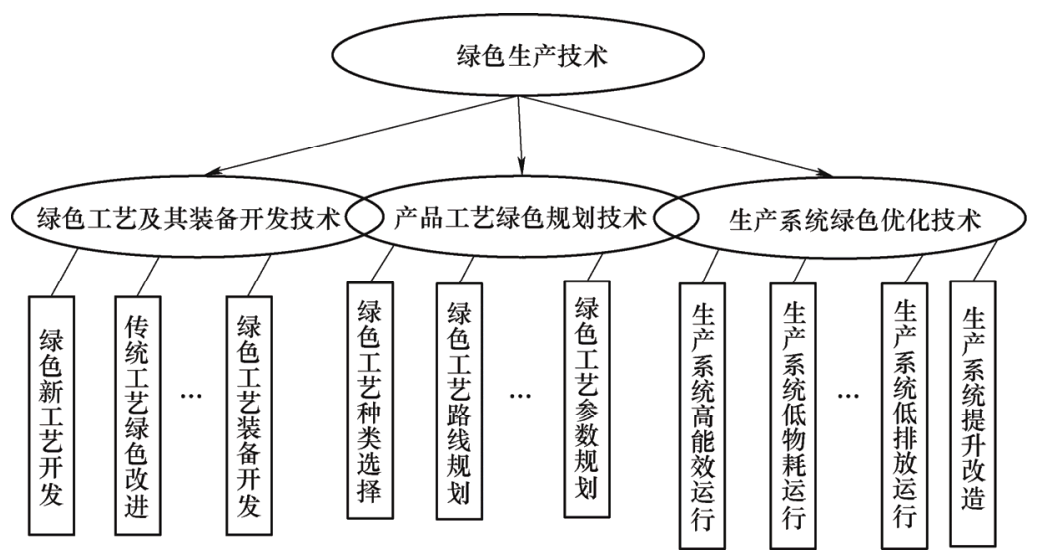

图 10 绿色生产技术体系

(3) 绿色运维技术。产品运维过程包括产品的 运行(或使用)、维护和维修等过程。基于现有研 究 ${ }^{[29-30]}$, 可以发现绿色运维技术主要包括绿色运行
技术、绿色维修维护技术以及支持技术, 如图 11 所示。其中, 绿色运行技术包括产品工况分析技术、 产品高能效运行技术、产品低排放运行技术、产品 
低物耗运行技术等; 产品绿色维护包括产品状态在 线诊断技术、故障预警技术、耗材更换决策优化技

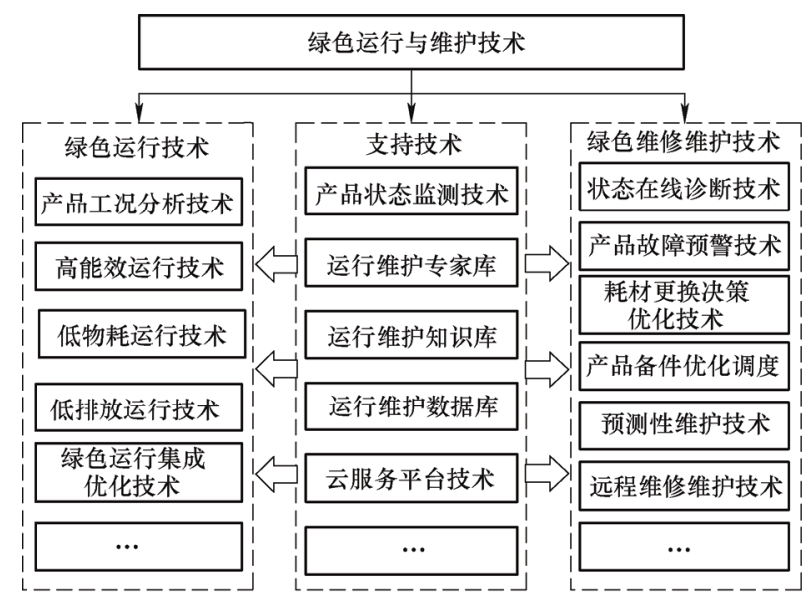

图 11 产品绿色运维的技术体系
术、产品备件优化调度技术、预测性维护技术以及 远程维修维护技术等; 支持技术包括产品状态检测、 运维知识库、运维数据库、运维专家库等。

（4）绿色回收处理与再制造技术。通过总结现 有研究 ${ }^{[6,31-32]}$, 可以发现绿色回收处理技术一般可 分为废旧产品可回收性分析与评价技术、废旧产品 绿色拆卸技术、废旧产品绿色清洗技术、废旧产品 材料绿色分离/回收技术、逆向物流管理技术等, 如 图 12 所示。对绿色再制造而言, 总结现有研究 ${ }^{[33-35]}$, 可建立如图 13 所示的绿色再制造技术体系，其中 主要包括再制造系统设计技术、再制造先进工艺技 术、再制造质量控制和再制造生产计划与控制等。 由于逆向物流技术习惯性作为供应链技术的一部 分, 在此将其归入绿色供应链部分。

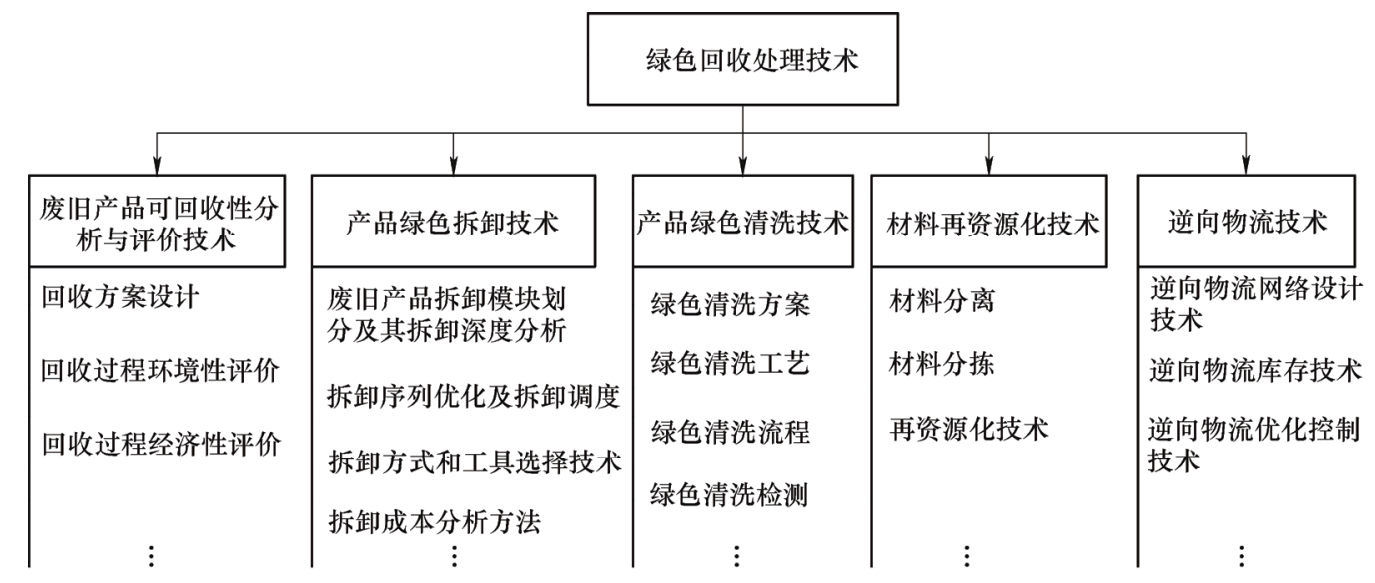

图 12 产品生命周期末端的绿色回收技术体系

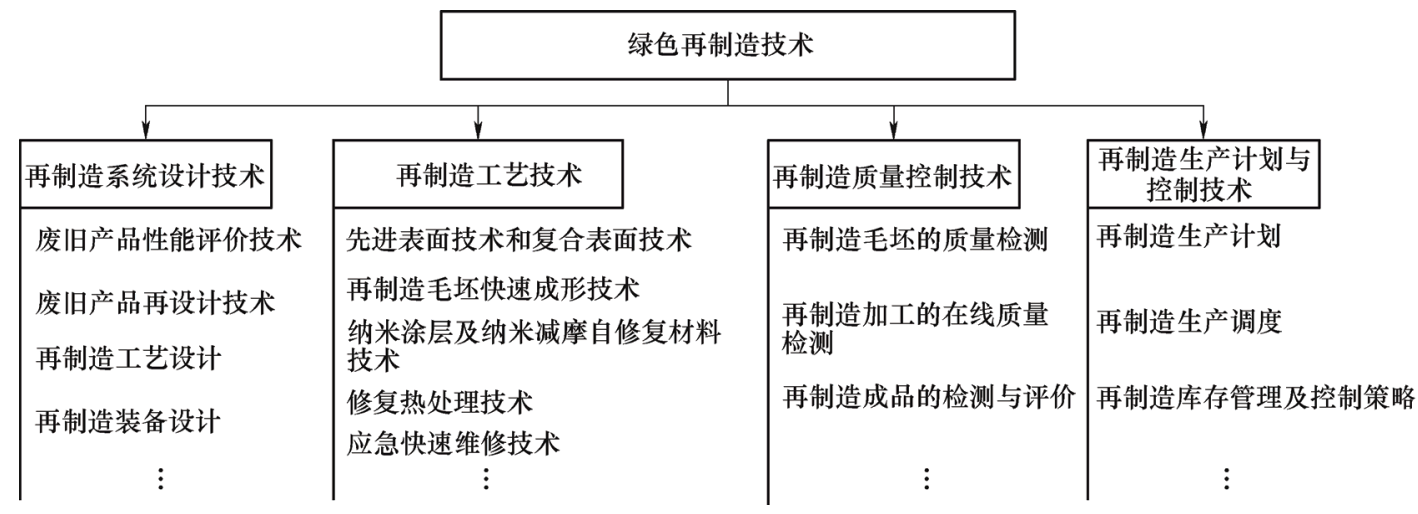

图 13 产品生命周期末端的绿色再制造技术体系

(5) 绿色供应链管理技术。供应链是指围绕核 心企业, 将所涉及的原材料供应商、制造商、分 销商、零售商直到最终用户等成员通过上游和/ 或下游成员链接所形成的网链结构。绿色供应链 是将绿色制造理念和要求融入供应链各个环节, 形成经济、社会和生态效益相协调的上下游供应 关系。因此, 在绿色设计、绿色生产、绿色运维以
及绿色回收与再制造的综合支持下，绿色供应链 旨在解决采购环节、营销环节、物流环节(包括正 向物流和逆向物流) 以及供应链协同所涉及的绿 色制造问题。总结现有研究 ${ }^{[36-40]}$, 可以建立由绿 色采购、绿色营销、绿色物流和绿色供应链协同 等 4 个方面构成的绿色供应链管理技术体系, 如 图 14 所示。 


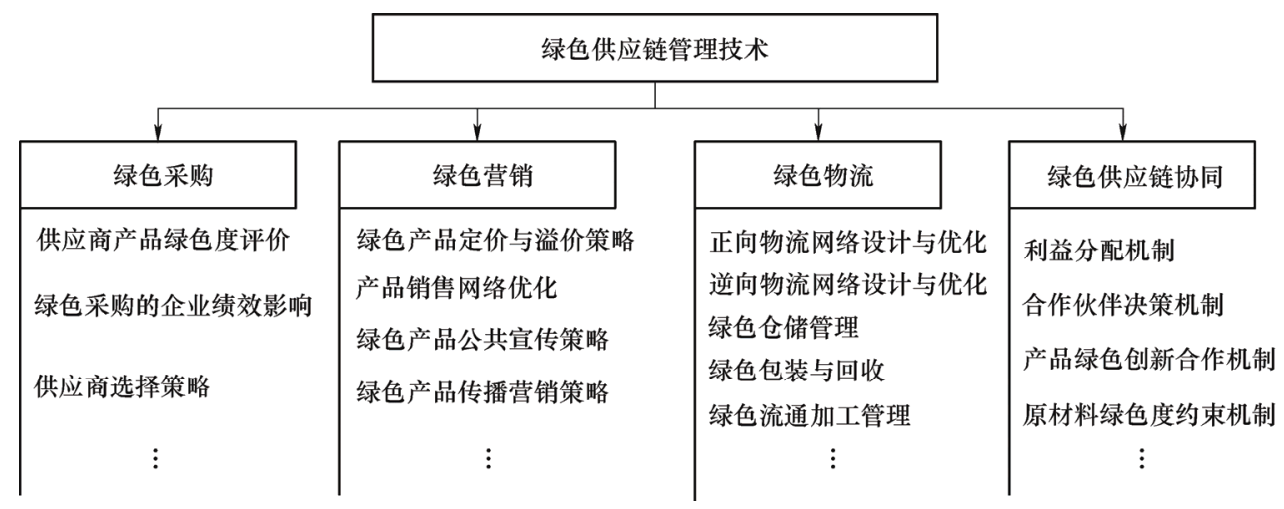

图 14 绿色供应链管理技术体系

(6) 产品生命周期管理技术。绿色制造是一项 复杂的系统工程。除了绿色设计、绿色生产、绿色 运维、绿色回收与再制造、绿色供应链管理等五类 专项技术之外, 还涉及一系列支持这些技术的集成 和应用的产品生命周期管理技术, 其中包括产品生
命周期建模、评估、数据管理等技术 ${ }^{[41-44]}$ 。

综上所述，可提出由五项专项技术和多项产品 生命周期管理技术组成的绿色制造技术体系框架, 如图 15 所示。绿色制造技术体系，以 6R 技术原则

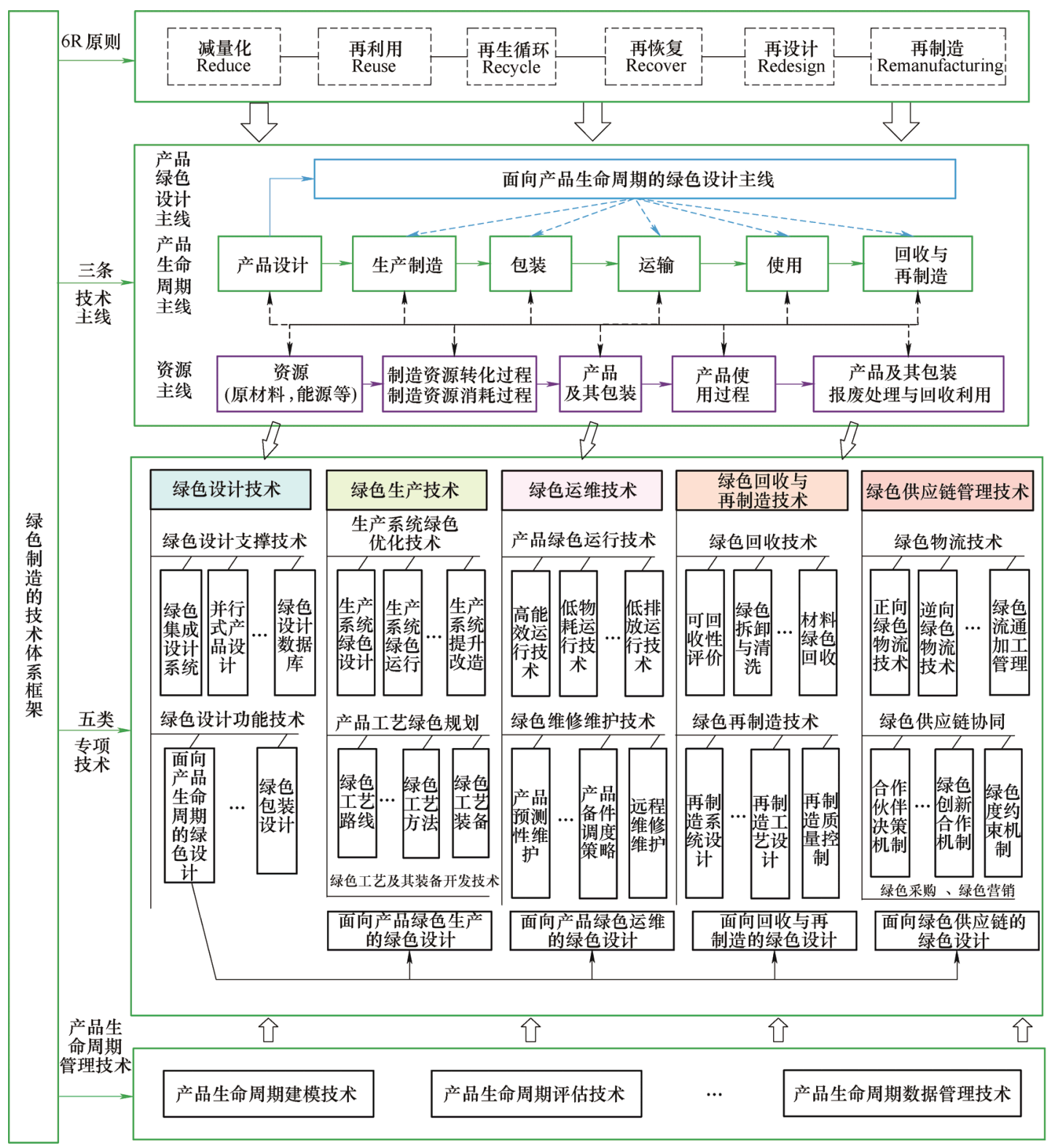

图 15 绿色制造的技术体系框架 
为指导, 以产品生命周期主线、资源主线、面向产 品生命周期的绿色设计主线为技术主线, 形成了绿 色设计技术、绿色生产技术、绿色运维技术、绿色 回收与再制造和绿色供应链管理 5 类专项技术和多 项产品生命周期管理技术。

\section{4 绿色制造理论技术综合体系框架}

综上所述, 可以建立如图 16 所示的绿色制造理
论技术的综合体系框架。其中，绿色制造的理论体 系为绿色制造指明了根本目标、根本途径和根本路 线，指导了绿色制造技术的原则和技术主线的形成; 同时，绿色制造技术体系，是绿色制造理论的实现 和应用, 也为绿色制造理论体系的发展和完善提供 了支撑。

其中，可以发现绿色制造理论体系与技术体系 之间至少存在以下几个方面的关联关系。

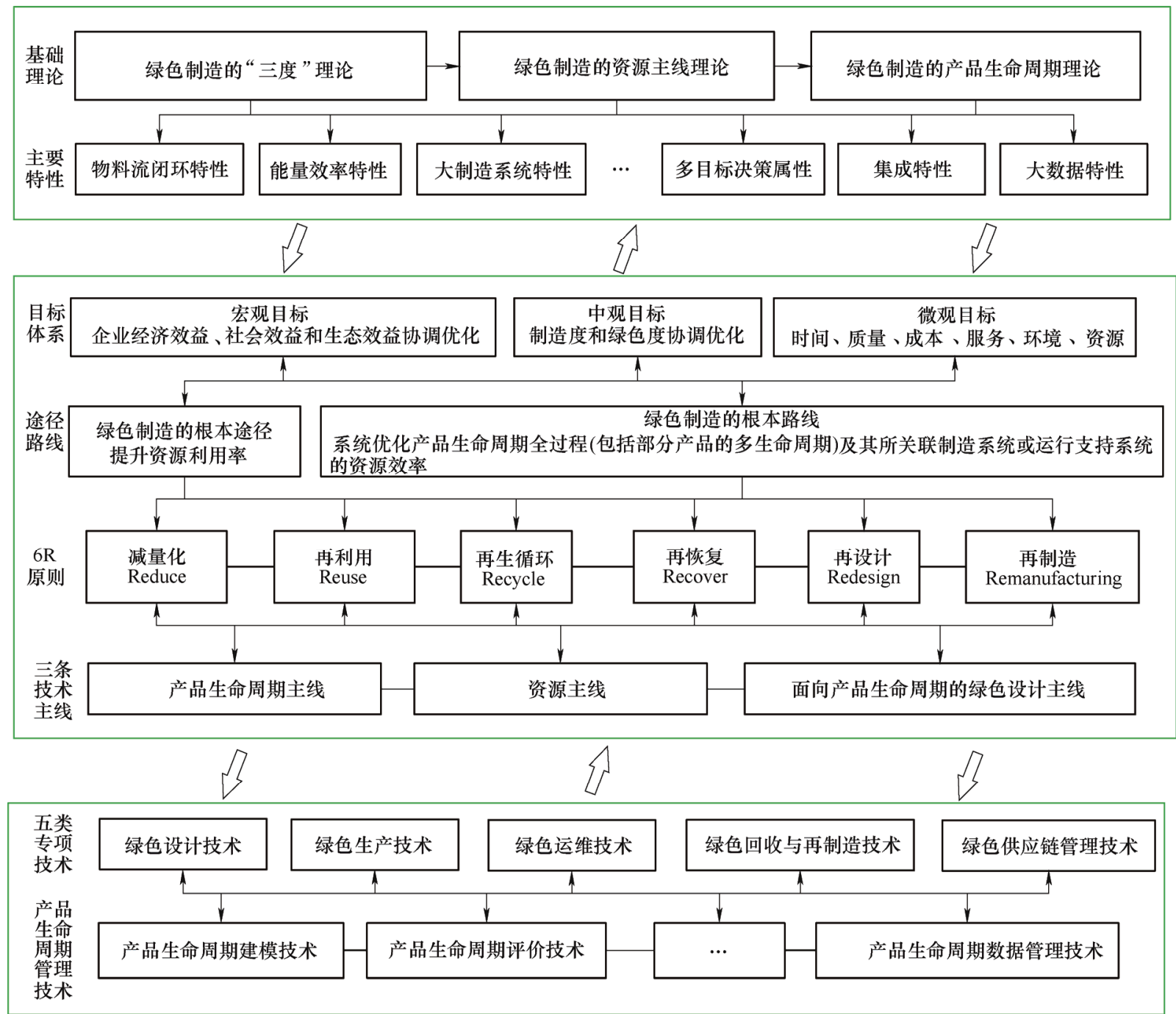

图 16 绿色制造理论与技术的综合体系框架

（1）绿色制造的三度理论和多目标决策属性形 成了绿色制造的宏观目标(即企业经济效益、社会效 益和生态效益协调优化)、中观目标(制造度和绿色 度的协调优化)和微观目标(时间、质量、成本、服 务、环境、资源协调优化), 为绿色制造技术提供了 决策目标。

（2）绿色制造的资源主线理论和产品生命周期 理论指导形成了绿色制造的 $6 \mathrm{R}$ 技术原则。其中, 资源主线理论着重要求绿色制造技术在产品生命周
期过程中实现制造资源的减量化、再利用、再生循 环; 同时，产品生命周期理论着重要求报废产品实 现回收再恢复、再设计和再制造。

（3）绿色制造的资源主线理论和产品生命周期 理论还指导形成了绿色制造的三条技术主线。其中， 产品生命周期主线推动形成了针对产品生命周期各 个环节的绿色制造技术以及贯穿各个生命周期环节 的产品生命周期管理技术; 资源主线则要求绿色制 造技术更加聚焦于产品生命周期各个环节的资源消 
耗过程及其带来的环境负面影响; 同时, 面向产品 生命周期的绿色设计主线强调了绿色设计技术在实 现绿色制造问题源头控制的重要性。
（4）绿色制造的六个主要特性，作为绿色制造 基础理论的补充，也为进一步完善绿色制造技术体 系提供了指导和支持(图 17)。

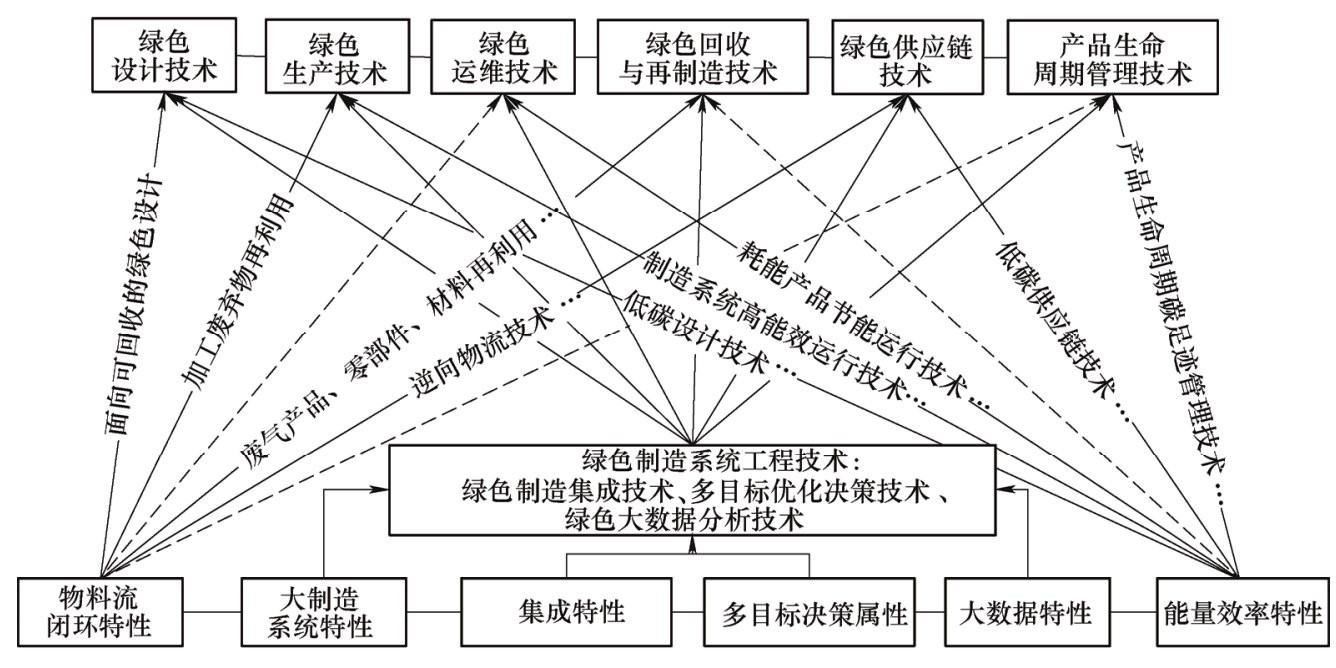

图 17 绿色制造的主要特性与部分重要技术的关联关系

比如绿色制造的能量效率特性引导了低碳设计 技术、制造系统高能效运行技术、耗能产品节能运 行技术、低碳供应链技术以及产品生命周期碳足迹 管理技术的发展。对应地, 绿色制造技术以绿色制 造的 $6 \mathrm{R}$ 原则为指导, 围绕产品生命周期主线、资 源消耗主体主线、面向产品生命周期的绿色设计主 线等三条主线而展开, 是绿色制造根本途径和根本 路线的具体体现。绿色制造技术的发展与应用, 可 为完善绿色制造理论体系提供实践理论支持。

\section{5 结论}

（1）更新和完善了绿色制造的定义: 绿色制造, 是一个综合考虑环境影响和资源消耗的现代化制造 模式; 其目标是使产品从设计、制造、包装、运输、 使用到回收处理的整个产品生命周期中, 对环境负 面影响极小, 资源利用率极高, 并使企业经济效益、 社会效益和生态效益协调优化。

(2) 提出了综合描述产品生命周期全过程的时 间、质量、成本和服务四个目标维度优劣程度的制 造度概念和综合描述资源和环境两个目标维度优劣 程度的绿色度概念, 基于此完善了绿色制造的 “三 度” 理论, 建立了由三个基础理论( “三度” 理论、 资源主线理论和生命周期理论) 和六个主要特性组 成的绿色制造理论体系, 初步明确了绿色制造的根 本问题、根本目标、根本途径以及根本路线。

(3) 建立了由 $6 R$ 技术原则、 3 条技术主线、 5
类专项技术(绿色设计技术、绿色生产技术、绿色运 维技术、绿色供应链管理技术和绿色回收与再制造 技术)以及产品生命周期技术组成的绿色制造技术 体系框架，初步明确了绿色制造的技术原则、技术 主线与技术体系。

上述理论和技术体系框架可为绿色制造理论和 技术深化研究提供参考支持。

\section{参 考 文 献}

[1] 曹华军, 李洪丞, 曾丹, 等. 绿色制造研究现状及未来 发展策略[J]. 中国机械工程, 2020，31(2): 135-144.

CAO Huajun, LI Hongcheng, ZENG Dan, et al. The state-of-art and future development strategies of green manufacturing $[\mathrm{J}]$. China Mechanical Engineering, 2020, 31(2): 135-144.

[2] STOCK T, SELIGER G. Opportunities of sustainable manufacturing in industry 4.0[J]. Procedia CIRP, 2016, 40: 536-541.

[3] The Government Office for Science. The future of manufacturing: A new era of opportunity and challenge for the UK project report[R]. London: The Governent Office for Scierce, 2013.

[4] 刘飞. 绿色制造[C]//先进制造模式与制造哲理研讨会 论文集大连: 大连理工大学出版社, 1997: 15-24.

LIU Fei. Green manufacturing[C]// Symposium on Advanced Manufacturing Model and Manufacturing Philosophy, Dalian: Dalian University of Technology 
Press, 1997: 15 24.

[5] 刘飞, 曹华军. 绿色制造的理论体系框架 $[\mathrm{J}]$. 中国机械 工程, 2000, 11(9): 10-13.

LIU Fei, CAO Huajun. The theory framework of green manufacturing[J]. China Mechanical Engineering, 2000, 11(9): 10-13.

[6] 刘飞, 曹华军, 张华, 等. 绿色制造的理论与技术 $[\mathrm{M}]$. 北京: 科学出版社, 2005 .

LIU Fei, CAO Huajun, ZHANG Hua, et al. Theory and technology of green manufacturing[M]. Beijing: Science Press, 2005.

[7] 刘飞, 李聪波, 曹华军, 等. 基于产品生命周期主线的 绿色制造技术内涵及技术体系框架 $[\mathrm{J}]$. 机械工程学报, 2009, 45(12): 115-120.

LIU Fei, LI Congbo, CAO Huajun, et al. Green manufacturing technology connotation and system framework based on product life cycle[J]. Journal of Mechanical Engineering, 2009, 45(12): 115-120.

[8] MELNGK S A, SMITH R T. Green Manufacturing[M]. Dearborn, USA: Society of Manufacturing Engineers, 1996.

[9] MOLDAVSKA A, WELO T. The concept of sustainable manufacturing and its definitions: A content-analysis based literature review[J]. Journal of Cleaner Production, 2017, 166(10): 744-755.

[10] KULDIP S S, VARINDER K M. A bibliometric analysis of green manufacturing and similar frameworks[J]. Management of Environmental Quality: An International Journal，2015，26(4): 566 - 587

[11] 王效科, 杨宁, 吴凡, 等. 生态效益及其特性[J]. 生态 学报, 2019, 39(15): 5433-5441.

WANG Xiaoke, YANG Ning, WU Fan, et al. Ecological benefit and its characteristics[J]. Acta Ecologica Sinica, 2019, 39(15): 5433-5441.

[12] DAVID A Dornfeld. Green manufacturing: Fundamentals and applications[M]. Berlin: Springer, 2013.

[13] 国家制造强国建设战略咨询委员会, 中国工程院战略 咨询中心. 绿色制造[M]. 北京: 电子工业出版社, 2016. Strategic Advisory Committee of National Manufacturing Power Construction, Strategic Advisory Center of Chinese Academy of Engineering. Green manufacturing [M]. Beijing: Electronics Industry Press, 2016.

[14] STARK R, BONVOISIN J. Sustainable manufacturing, challenges, solutions and implementation perspectives[M]. New York: Springer. 2017.
[15] 中国科学院可持续发展研究组. 中国可持续发展战略 报告[R]. 北京: 科学出版社, 1999.

Research Group on Sustainable Development, Chinese Academy of Sciences. Report on China's sustainable development strategy[R]. Beijing: Science Press, 1999.

[16] 刘飞, 张华, 陈晓慧. 绿色制造的决策框架模型及其应 用 $[\mathrm{J}]$. 机械工程学报, 1999, 35(5): 3-5.

LIU Fei , ZHANG Hua, CHEN Xiaohui. A decision-making framework model of green manufacturing[J]. Journal of Mechanical Engineering, 1999, 35(5): 3-5.

[17] 江志刚, 张华, 肖明. 面向绿色制造的生产过程多目标 集成决策模型及应用 $[\mathrm{J}]$. 机械工程学报, 2008，44(4): 41-46.

JIANG Zhigang, ZHANG Hua , XIAO Ming. Multi-objective integrating decision-making model and its application of production process for green manufacturing[J]. Journal of Mechanical Engineering, 2008, 44(4): 41-46.

[18] 刘飞, 张华, 陈晓慧. 绿色制造的集成特性和绿色集成 制造系统[J]. 计算机集成制造系统，1999，5(4): 9-13. LIU Fei, ZHANG Hua, CHEN Xiaohui. Integration characteristics of green manufacturing and green integrated manufacturing systems[J]. Computer Integrated Manufacturing System, 1999, 5(4): 9-13.

[19］刘飞, 刘培基, 李聪波, 等. 制造系统能量效率研究的 现状及难点问题[J]. 机械工程学报, 2017, 53(5): 1-11. LIU Fei, LIU Peiji, LI Congbo, et al. The status and difficult problems of research on the energy efficiency of manufacturing systems[J]. Journal of Mechanical Engineering, 2017, 53(5): 1-11.

[20] AHMAD S, WONG K Y, TSENG M L, et al. Sustainable product design and development: A review of tools, applications and research prospects[J]. Resources , Conservation and Recycling, 2018，132: 49-61.

[21] JHA N. Green design and manufacturing for sustainability[M]. Florida: CRC Press, 2015.

[22] 刘志峰. 绿色设计方法、技术及其应用[M]. 北京：国 防工业出版社, 2008.

LIU Zhifeng. Green design method, technology and its application[M]. Beijing: National Defense Industry Press, 2008.

[23] 王晓伟, 李方义. 机电产品绿色设计与生命周期评价 [M]. 北京：机械工业出版社，2015.

WANG Xiaowei, LI Fangyi. Green design and life cycle 
evaluation of mechanical and electrical products[M].

Beijing: China Machinery Industry Press, 2015.

[24] 单忠德, 胡世辉. 机械制造传统工艺绿色化 [M]. 北京: 机械工业出版社, 2013.

SHAN Zhongde, HU Shihui. Greening of traditional machinery manufacturing process $[\mathrm{M}]$. Beijing : Machinery Industry Press, 2013.

[25] DAVIM J P. Green manufacturing processes and systems[M]. Berlin: Springer, 2013

[26] 何彦, 刘飞, 曹华军, 等. 面向绿色制造的机械加工系 统任务优化调度模型 $[\mathrm{J}]$. 机械工程学报, 2007, 43(4): 27-33.

HE Yan, LIU Fei, CAO Huajun, et al. Job scheduling model of machining system for green manufacturing[J]. Journal of Mechanical Engineering, 2007, 43(4): 27-33.

[27] 谭显春, 刘飞, 曹华军, 等. 绿色制造的一种工艺路线 决策模型及其求解算法 [J]. 机械工程学报, 2004, 40(4): 154-159.

TAN Xianchun, LIU Fei, CAO Huajun, et al. Decision-making model for process route in green manufacturing and its algorithms[J]. Journal of Mechanical Engineering, 2004, 40(4): 154-159.

[28] 曹华军, 刘飞, 何彦, 等. 面向绿色制造的机床设备选 择模型及其应用[J]. 机械工程学报, 2004, 40(3): 26-30. CAO Huajun, LIU Fei, HE Yan, et al. Machine tool selection model and its application for green manufacturing[J]. Journal of Mechanical Engineering, 2004, 40(3): 26-30.

[29] AJUKUMAR V, GANDHI O P. Evaluation of green maintenance initiatives in design and development of mechanical systems using an integrated approach[J]. Journal of Cleaner Production, 2013 (51): 34-46.

[30] GOYAL D, PABLA B S. Condition based maintenance of machine tools-A review[J]. CIRP Journal of Manufacturing Science \& Technology, 2015, 10: 24-35.

[31] 代䵀, 马祖军. 废旧家电回收处理体系及管理机制 $[\mathrm{M}]$. 北京: 科学出版社, 2010 .

DAI Ying, MA Zujun. Waste home appliance recycling and treatment system and management mechanism [M]. Beijing: Science Press, 2010.

[32] SELIGER G , BAYAT N. Sustainability in manufacturing: Recovery of resources in product and material cycles[M]. Berlin: Springer, 2007.

[33] 徐滨士. 再制造工程基础及其应用 $[\mathrm{M}]$. 哈尔滨：哈尔 滨工业大学出版社, 2005.
XU Binshi. Foundation and application of remanufacturing engineering[M]. Harbin: Harbin Institute of Technology Press, 2005.

[34] KERIN M, PHAM D T. A review of emerging industry 4.0 technologies in remanufacturing[J]. Journal of Cleaner Production, 2019, 237: 117805

[35] HSIEH H N, MEEGODA J N. SALAH E. Sustainable industrial design and waste management - cradle -tocradle for sustainable development[M]. Cairo: Academic Press, 2007.

[36] 但斌, 刘飞. 绿色供应链及其体系结构研究[J].中国机 械工程, 2000，11(11): 1232-1234.

DAN Bin, LIU Fei. Research on green supply chain and its architecture [J]. China Mechanical Engineering, 2000, 11(11): 1232-1234.

[37] 朱庆华, 阎洪. 绿色供应链管理 理论与实践 $[\mathrm{M}]$. 北 京: 科学出版社, 2013.

ZHU Qinghua, YAN Hong. Theory and practice of green supply chain management $[\mathrm{M}]$. Beijing: Science Press, 2013.

[38] CHAN F T S, LI N, CHUNG S H, et al. Management of sustainable manufacturing systems-a review on mathematical problems[J]. International Journal of Production Research， 2017， 55(3-4): 1-16.

[39] ANSARI Z N, KANT R. A state-of-art literature review reflecting 15 years of focus on sustainable supply chain management[J]. Journal of Cleaner Production, 2017, 142: 2524-2543.

[40] DE OLIVEIRA U R, ESPINDOLA L S, DA SILVA I R, et al. A systematic literature review on green supply chain management : Research implications and future perspectives[J]. Journal of Cleaner Production, 2018, 187: $537-561$

[41] GBEDEDO M A, LIYANAGE K, GARZA-REYES J A. Towards a life cycle sustainability analysis: a systematic review of approaches to sustainable manufacturing $[\mathrm{J}]$. Journal of Cleaner Production, 2018: 1002-1015.

[42] 邵新宇, 邓超, 吴军, 等. 产品设计中生命周期评价与 生命周期成本的集成与优化 [J].机械工程学报，2008， 44(9): $13-20$

SHAO Xinyu, DENG Chao, WU Jun, et al. Integration and optimization of life cycle assessment and life cycle costing for product design[J]. Journal of Mechanical Engineering, 2008, 44(9): 13-20.

[43] THIES C, KIECKHFER K, SPENGLER T S, et al. 
Operations research for sustainability assessment of products: A review[J]. European Journal of Operational Research, 2019, 274(1): 1-11.

[44] 任杉, 张映锋, 黄涁涁. 生命周期大数据驱动的复杂产 品智能制造服务新模式研究 [J]. 机械工程学报, 2018, 54 (22): 194-203.

REN Shan, ZHANG Yingfeng, HUANG Binbin. New pattern of lifecycle big-data-driven smart manufacturing service for complex product[J]. Journal of Mechanical
Engineering, 2018, 54 (22): 194-203.

作者简介: 刘培基, 男, 1994 年出生, 博士后。主要研究方向为绿色制 造、制造系统能量效率。

E-mail: liupeiji@cqu.edu.cn

刘飞, 男, 1948 年出生, 博士, 教授, 博士研究生导师。主要研究方 向为绿色制造、制造系统工程和数字化制造。

E-mail: fliu@cqu.edu.cn

王旭, 女, 1963 年出生, 博士, 教授, 博士研究生导师。主要研究方向 为现代物流与绿色供应链、企业信息化。

E-mail:wx921@163.com 